\title{
DIVERSIFIKASI PRODUK KACANG TANAH BAGI MASYARAKAT DESA RASAU JAYA SATU KALIMANTAN BARAT
}

\author{
Intan Syahbanu ${ }^{1}$, Helen Sastypratiwi ${ }^{2}$, Nurul Bariyah ${ }^{3}$ \\ ${ }^{1}$ Fakultas MIPA Universitas Tanjungpura. Email: intan.syahbanu@chemistry.untan.ac.id \\ ${ }^{2}$ Fakultas Teknik Universitas Tanjungpura. Email: helensastypratiwi@gmail.com \\ ${ }^{3}$ Fakultas Ekonomi Universitas Tanjungpura. Email: nurulb hamzar@yahoo.com
}

\begin{abstract}
Peanut is one of the commodities from Rasau Jaya Satu. Varieties of the peanuts in this village are the large one, with 3-4 beans of one pieces, therefore they have great potency to be developed and marketed outside the village. However, the marketing of peanuts are in raw materials without further process. Through Program Kemitraan Masyarakat (PKM), institution of higher education plays role in transferring knowledge about product diversification from the peanuts. The products transferred to this program include onion nuts, ordinary and spicy egg nuts, peanut candy, bean dodol, and peanut butter along with the correct and attractive packaging method. The PKM team also facilitated the establishment of business forums and training activities in order to improve the ability and insight for citizens. The training that has been carried out were the introduction of UMKM and entrepreneurship and product manufacturing training. Through this activity, it is hoped that it can improve the skills of citizens so that it becomes a new business opportunity in processing peanuts.
\end{abstract}

Keywords: Peanuts, product diversification, UMKM

\begin{abstract}
ABSTRAK
Kacang tanah merupakan salah satu komoditas dari Desa Rasau Jaya Satu. Varietas kacang tanah yang ada di desa ini adalah kacang jenis besar dengan biji 3-4, sehingga memiliki potensi besar untuk dikembangkan dan dipasarkan di luar desa. Akan tetapi, penjualan kacang tanah hanya dalam bentuk mentahnya saja, tanpa pengolahan lebih lanjut. Melalui Program Kemitraan Masyarakat (PKM), institusi perguruan tinggi berperan dalam mentransfer ilmu, dalam hal diversifikasi produk berbasis kacang tanah. Produk yang ditransfer pada program ini antara lain kacang bawang, kacang telur biasa dan pedas, permen kacang, dodol kacang, dan selai kacang beserta cara pengemasannya yang benar dan menarik. Tim PKM juga memfasilitasi pembentukan wadah usaha dan kegiatan pelatihan dalam rangka meningkatkan kemampuan dan wawasan bagi warga. Pelatihan yang telah dilakukan antara lain adalah pengenalan UMKM dan kewirausahaan dan pelatihan pembuatan produk. Melalui kegiatan ini diharapkan dapat meningkatkan keterampilan warga sehingga menjadi peluang usaha baru dalam pengolahan kacang tanah.
\end{abstract}

Kata Kunci: Kacang tanah, diversifikasi produk, UMKM

\section{PENDAHULUAN}

Desa Rasau Jaya Satu merupakan salah satu kawasan yang dikembangkan oleh pemerintah pusat sebagai Kota Terpadu Mandiri. Desa ini terletak di Kecamatan Rasau Jaya Kabupaten Kubu Raya Kalimantan Barat. Pengembangan daerah sebagai Kota Terpadu Mandiri dilakukan untuk mensukseskan program transmigrasi dan pemerataan penduduk.

Berdasarkan data Profil Desa Rasau Jaya Satu Tahun 2015, tercatat jumlah total penduduk sebanyak 7.340 orang, dengan proporsi laki-laki 3.674 orang dan perempuan 
3.666 orang. Mayoritas penduduk adalah etnis Jawa sejumlah 6.564 orang, dan etnis lain seperti Madura, Melayu, Dayak, Bali, Sunda dan Cina. Luas wilayah Desa Rasau Jaya Satu mencapai $13,92 \mathrm{Ha} / \mathrm{m}^{2}$, dengan topografi wilayah dataran dan curah hujan sedang menjadikan desa ini potensial dalam bidang pertanian dan perkebunan (kemendesa.go.id).

Salah satu komoditas yang berpotensi untuk dikembangkan secara luas adalah kacang tanah. Data monografi desa tahun 2012 menunjukkan hasil kacang tanah di Desa Rasau Jaya 1 mencapai lebih dari 100 ton (Meliani, 2012). Menurut data profil Desa Rasau Jaya 1 tahun 2015, komoditas kacang tanah yang dihasilkan sejumlah 1,80 ton per hektar.

Permasalahan yang muncul dalam usaha kacang tanah ini awalnya adalah kurangnya inovasi produk berbasis kacang tanah. Selama ini, kacang tanah di Rasau Jaya 1 umumnya dijual dalam bentuk mentah saja atau hanya digoreng biasa. Selain itu, dari segi pengemasan juga hanya digunakan bungkus plastik biasa sehingga tampilan kurang menarik. Permasalahan lain yang penting adalah mengenai pembukuan keuangan usaha dan pemasaran produk yang selama ini hanya bergerak di sekitar Rasau Jaya. Oleh karena itu, melalui Program Kemitraan Masyarakat, dibentuk wadah kegiatan usaha yang bergerak dalam usaha produk berbasis kacang tanah. Wadah kegiatan ini selanjutnya diberi pembinaan mulai dari diversifikasi produk berbasis kacang tanah, hingga pemasaran produk keluar daerah Rasau Jaya.

Diversifikasi produk kacang tanah merupakan solusi dalam rangka memperluas ruang lingkup pemasaran produk (Yulifianti, dkk). Produk olahan dari kacang tanah yang dapat diproduksi antara lain kacang bawang, kacang telur original, kacang telur pedas, dodol kacang, permen kacang dan selai kacang. Untuk mendukung hal tersebut dibutuhkan pengemasan dan strategi pemasaran yang baik. Pengemasan dilakukan dengan laminating, vakum dan dalam kemasan kotak, agar dapat lebih menarik.

Program Kemitraan Masyarakat ini melibatkan ibu-ibu rumah tangga. Rentang usia peserta program mulai dari 18 - 45 tahun. Pelibatan ibu-ibu rumah tangga dalam kegiatan ini adalah di bagian produksi, pengemasan dan pemasaran. Hal ini diharapkan dapat mendongkrak perekonomian dan khususnya komoditas kacang tanah.

\section{METODE PELAKSANAAN}

Metode pelaksanaan kegiatan dan pendekatan yang digunakan dalam kegiatan PKM ini terbagi dalam 4 tahap, yaitu Pendekatan Struktural, Pendekatan Partisipatif dan Instruksional, Pelatihan dan Workshop serta Praktek dan Pendampingan.

Pendekatan Struktural dilakukan dengan melakukan pendekatan dengan kepala desa beserta perangkat desa lainnya dalam menjaring informasi dan sebagai penghubung antara tim PKM dengan kelompok warga dalam program yang akan diimplementasikan. Pendekatan Partisipatif dan Instruksional dilakukan sebagai upaya untuk mengetahui dan mengenal karakteristik kelompok warga dan masyarakat sekitar, agar lebih mudah dalam transfer informasi dan iptek yang akan diterapkan.

Pelatihan dan workshop dilakukan dengan memberikan materi tentang diversifikasi produk kacang tanah, pembukuan, desain logo dan kemasan serta 
penggunaan IT dalam pengembangan usaha mikro kacang tanah. Praktek dan Pendampingan dilakukan setelah mendapatkan materi pada pelatihan, kelompok warga yang dibina akan didampingi untuk melakukan praktek dalam pembuatan produk, pengemasan dan persiapan serta sertifikasi produk.

\section{HASIL DAN PEMBAHASAN}

\section{Diversifikasi Produk dan Pengemasan Berbasis Kacang Tanah}

Program Kemitraan Masyarakat ini menghasilkan karya berupa produk-produk berbasis kacang tanah beserta kemasan, desain logo dan merk dagang yang akan digunakan. Produk yang dihasilkan disajikan pada Gambar 1. Produk ini antara lain, kacang bawang gurih, kacang telur original dan kacang telur pedas, permen kacang, dodol kacang dan selai kacang.

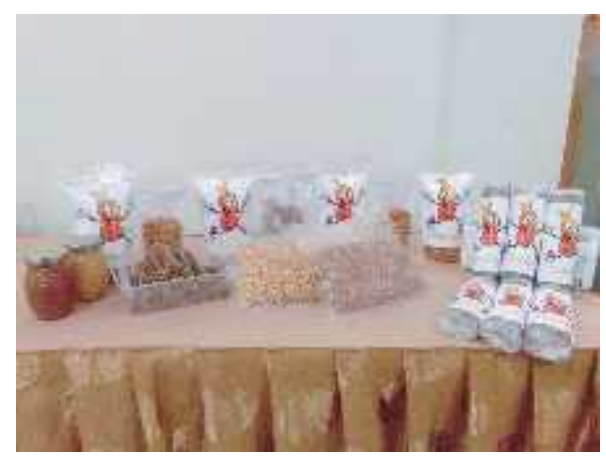

Gambar 1 Diversifikasi Produk berbasis Kacang Tanah

Salah satu produk unggulan dari PKM ini adalah kacang telur pedas. Kacang telur dibuat dalam 4 tingkat rasa pedas, yakni tidak pedas, sedikit pedas, pedas dan sangat pedas. Dasar pembuatan kacang telur pedas ini karena melihat pasar dan minat masyarakat yang tinggi terhadap produk-produk dengan rasa pedas. Produk permen kacang yang dihasilkan memiliki cita rasa tradisional dengan penggunaan gula jawa sebagai pemanis.
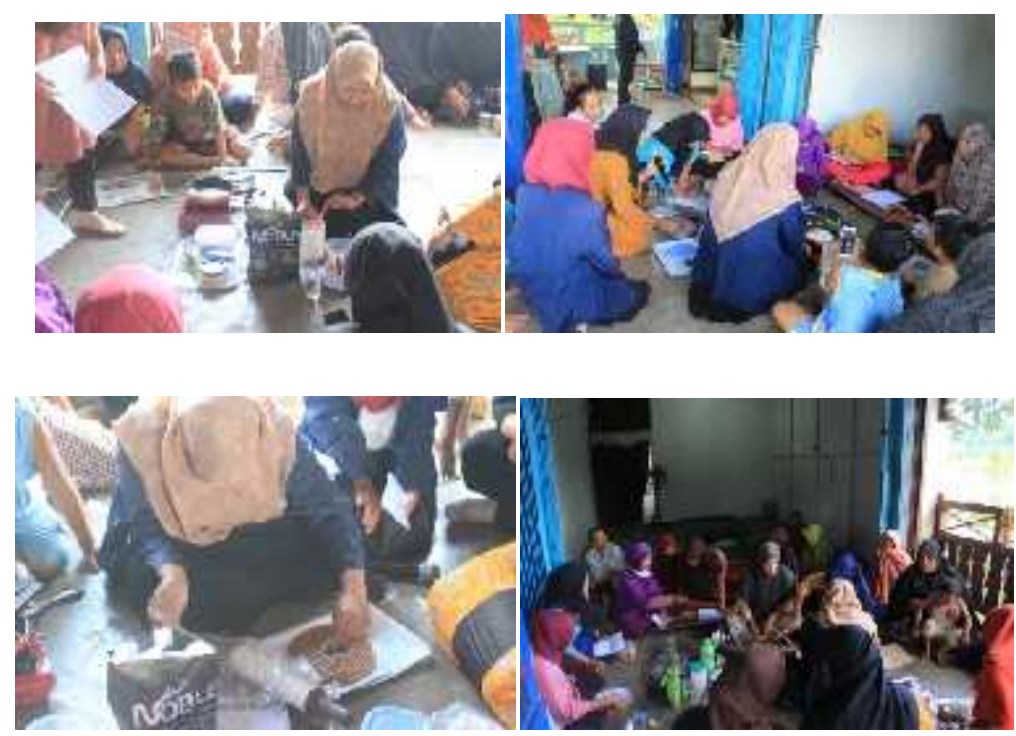

Gambar 2 Pelatihan Pembuatan Produk Permen kacang dan Dodol kacang 
Produk dodol kacang dibuat dengan bahan kacang, santan, tepung ketan dan gula yang dimasak hingga membentuk adonan dodol. Produk ini memiliki ketahanan yang baik sehingga cocok juga digunakan sebagai oleh-oleh khas Rasau Jaya. Selai kacang dibuat dalam 2 varian, yaitu selai kacang original dan selai kacang coklat.

Program PKM juga memperkenalkan beberapa teknik pengemasan produk sehingga tampilannya mampu bersaing dengan produk pasar lainnya. Untuk produk kacang, pengemasan menggunakan standing pouch bening yang ditempel stiker menarik. Produk permen juga menggunakan kemasan yang di press agar kedap udara, sehingga kualitas produk yg dihasilkan terjaga. Selain itu, produk kacang juga ada yang dikemas dengan kemasan vakum, sehingga kerenyahan kacang dapat terjaga. Untuk produk selai, dilakukan tahapan sterilisasi terlebih dahulu sebelum pengemasan. Teknik sterilisasi yang benar juga ditransfer ke warga sehingga dapat mengemas produk dengan baik (Ismiati dkk, 2018).

\section{Pelatihan Kewirausahaan dan UMKM}

Salah satu upaya untuk mendorong pertumbuhan ekonomi daerah adalah dengan peningkatan ekonomi rumah tangga melalui pembukaan lapangan usaha. Pembukaan lapangan usaha yang paling mudah adalah melalui sektor Usaha Mikro, Kecil dan Menengah (UMKM). Saat ini, Dinas Koperasi Usaha Mikro dan Perdangan Pontianak sedang mencanangkan program untuk memfasilitasi produk-produk UMKM agar dapat masuk ke pasar dan toko modern, sehingga ruang gerak bagi pelaku UMKM akan lebih terbuka (Pontianak Post, 2018)

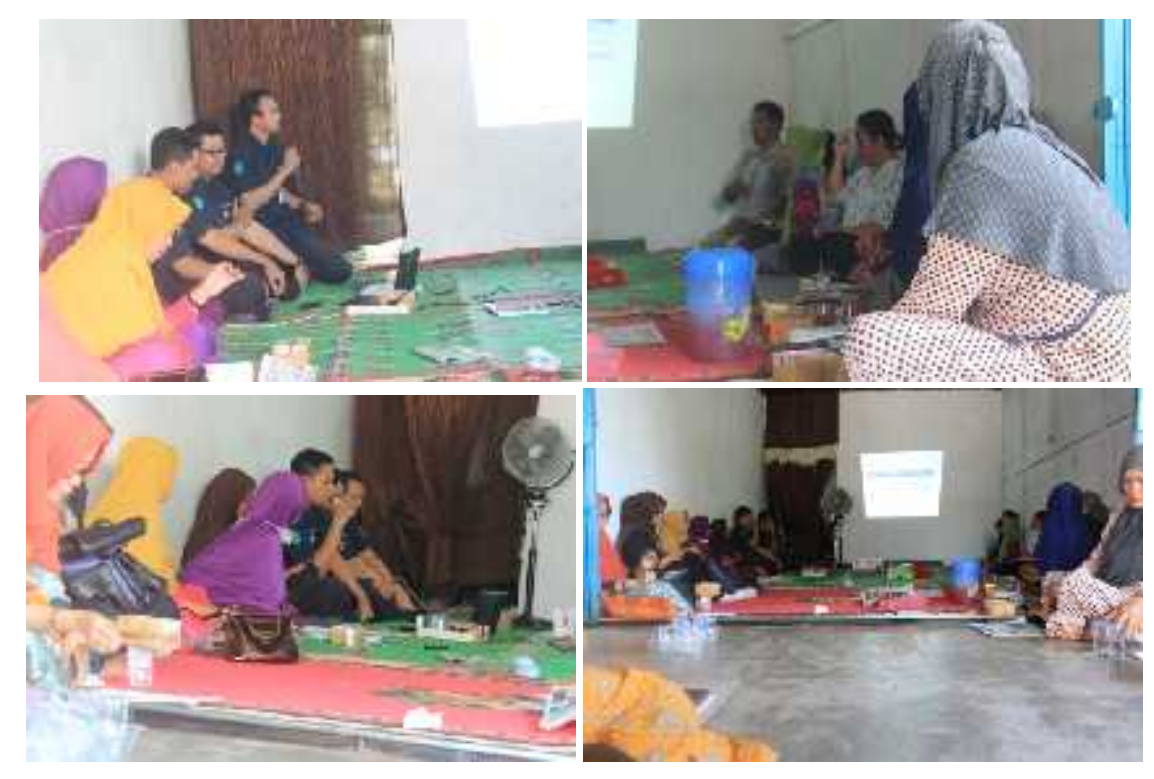

Gambar 3 Pelatihan Kewirausahaan dan UMKM

Berdasakan hal tersebut, tim PKM Universitas Tanjungpura bersama Unit Usaha Mikro Bank Pembangunan Daerah Kalimantan Barat ingin berperan serta melalui pelatihan tentang kewirausahaan dan UMKM dengan sasaran segmen masyarakat ibuibu rumah tangga dan remaja putri di. Adapun tujuan pelatihan ini adalah untuk 
mendongkrak semangat berwirausaha bagi Ibu-ibu dan remaja putri di Desa Rasau Jaya Satu.

Kegiatan dimulai dengan komunikasi dengan pihak desa maupun perbankan. Program pelatihan dikemas dalam bentuk pemaparan materi dan diskusi serta tanya jawab interaktif. Peserta dalam pelatihan ini terdiri dari 21 orang. Pada pelatihan ini diberikan wawasan mengenai wirausaha dan UMKM serta peluang-peluang modal usaha serta kisah sukses para pelaku UMKM, sehingga para peserta dapat termotivasi untuk berkegiatan usaha.

\section{Evaluasi Pelaksanaan Dan Keberlanjutan Program}

Pelaksanaan program PKM ini telah membuka pandangan warga tentang produk pertanian kacang tanah yang dapat ditingkatkan daya jualnya melalui diversifikasi. Selama ini, kacang tanah yang dihasilkan dijual langsung dalam bentuk mentahnya dan hanya di sekitar Rasau Jaya saja. Lemahnya daya jual, ruang lingkup pemasaran yang sempit serta kacang tanah mentah yang tidak tahan lama karena mudah berkecambah menyebabkan pengembangan komoditas tersebut lambat. Melalui program diversifikasi produk berbasis kacang tanah, masyarakat jadi memiliki bekal untuk memodifikasi dan berkreasi dengan bahan dasar kacang tanah yang berpotensi ekonomi. Hasil pendampingan tim PKM menunjukkan bahwa masyarakat telah mampu membuat produk kacang bawang gurih, kacang telur original dan pedas, permen kacang, dodol kacang dan selai kacang. Terkait pengemasan dan labeling, tim PKM membantu masyarakat mempersiapkan desain label stiker yang menarik dengan merk "Kacang RaJa" asli Rasau Jaya. Teknik pengemasan juga diberikan ke warga pada saat pendampingan. Produk yang telah dihasilkan juga akan dipersiapkan untuk pengurusan ijin P-IRT sehingga pemasaran dapat lebih luas.

Pada program pelatihan kewirausahaan dan UMKM, masyarakat cukup antusias atas pemaparan pemateri yang disampaikan. Selama pelaksanaan terjadi diskusi interaktif sehingga warga lebih bersemangat untuk berwirausaha. Langkah selanjutnya, dari peserta yang hadir, telah dibentuk komunitas usaha Ibu-ibu di Rasau Jaya wadah aktivitas dan kreativitas warga dalam mengolah produk berbasis kacang tanah. Melalui PKM ini juga komunitas usaha tersebut memperoleh hibah peralatan yang digunakan sebagai modal awal usaha, baik untuk produksi maupun pengemasan. Selain pendampingan dalam hal diversifikasi produk dan pengemasan, tim PKM Universitas Tanjungpura juga memberikan pendampingan dalam pemasaran hingga keluar Rasau Jaya.

Melalui kegiatan ini diharapkan dapat bermanfaat dan menimbulkan jiwa kewirausahaan, sehingga terbentuk pengusaha-pengusaha UMKM baru ke depannya. Dengan demikian, akan tercipta lapangan usaha baik untuk dirinya sendiri maupun masyarakat sekitarnya, sehingga mendukung perkembangan ekonomi masyarakat yang berkelanjutan.

\section{SIMPULAN}

Program Kemitraan Masyarakat telah memberikan wawasan bagi warga mengenai diversifikasi produk berbasis kacang tanah dan teknik pengemasan yang baik 
dan menarik. Melalui program ini juga telah terbentuk wadah usaha mikro bagi Ibu-ibu di Rasau Jaya Satu yang menjalankan aktivitas pengolahan produk-produk dari kacang tanah sehingga nilai ekonomi komoditas tersebut meningkat. Rancangan kegiatan ke depan adalah menggiatkan kegiatan produksi dan memperluas pemasaran produk hingga keluar daerah.

\section{UCAPAN TERIMA KASIH}

Ucapan terima kasih diberikan kepada Direktorat Riset dan Pengabdian Kepada Masyarakat Kementerian Riset Teknologi dan Pendidikan Tinggi atas pendanaan kegiatan melalui Program Kemitraan Masyarakat (PKM).

\section{DAFTAR RUJUKAN}

Ismiyati, Nugrahani, R.A., Hendrawati, T.Y. (2018). Diversifikasi menjadi Produk Selai dan Peningkatan Mutu Jus Aloe Vera di SIGMA Food Sawangan Depok. J. PKM. 3 , (2) 178-183.

Kantor Desa Rasau Jaya 1. (2015). Profil Desa Rasau Jaya 1. Rasau Jaya

https://www.google.co.id/maps/dir/Universitas+Tanjungpura/Rasau+Jaya+Satu/ diakses pada 2 Juli 2017

https://www.kemendesa.go.id/ diakses pada 22 Juni 2017.

Meliani, D. (2012), Daya Dukung Lingkungan Kecamatan Rasau Jaya Berdasarkan Ketersediaan dan Kebutuhan Lahan

Pontianak Post. (2018). Produk UMKM Bakal Masuk Toko Moderen, diterbitkan pada 14 Juli 2018.

Yulifianti, R., Santosa, B.A.S., Widowati, S., Teknologi Pengolahan dan Produk Olahan Kacang Tanah, Monograf Balitkabi no.13: 377-393. 